Pacific Journal of Mathematics

ON DECOMPOSITION OF TRANSFORMATIONS IN INFINITE 


\title{
ON A DECOMPOSITION OF TRANSFORMATIONS IN INFINITE MEASURE SPACES
}

\author{
RYOTARO SATO
}

A decomposition theorem for a measure preserving transformation $T$ on a $\sigma$-finite and infinite measure space $(\Omega, \mathscr{B}, m)$ is proved and ergodic theorems are considered.

1. Introduction. A measure preserving transformation $T$ on $(\Omega, \mathscr{B}, m)$ is called of zero type, if

$$
\lim _{N \rightarrow \infty} m\left(T^{-N} A \cap A\right)=0
$$

for any measurable set $A$ with $m(A)<\infty$. The transformation $T$ is called of positive type, if

$$
\limsup _{N \rightarrow \infty} m\left(T^{-N} A \cap A\right)>0
$$

for any measurable set $A$ with $m(A)>0$. Krengel and Sucheston [4] showed that every measure preserving transformation can be decomposed into two measure preserving transformations, acting on disjoint invariant measurable sets, such that one of them is of zero type and the other is of positive type. However it seems that, in order to apply this result to ergodic theory, more detailed considerations are necessary. In this paper, we shall improve the result by introducing new concept of positivity and then, applying the obtained result, extend ergodic theorems of Brunel and Keane [1] to infinite measure spaces.

2. The decomposition theorem. A measure preserving transformation $T$ will be called of weakly positive type, if $T$ is of positive type and satisfies

$$
\lim _{N \rightarrow \infty} \frac{1}{N} \sum_{k=0}^{N-1} m\left(T^{-k} A \cap A\right)=0
$$

for any measurable set $A$ with $m(A)<\infty$. The transformation $T$ will be called of strongly positive type, if $T$ satisfies

$$
\limsup _{N \rightarrow \infty} \frac{1}{N} \sum_{k=0}^{N-1} m\left(T^{-k} A \cap A\right)>0
$$

for any measurable set $A$ with $m(A)>0$.

THEOREM 1. If $T$ is a measure preserving transformation on 
$(\Omega, \mathscr{B}, m)$, then $\Omega$ uniquely decomposes into three measurable sets $\Omega_{0}$, $\Omega_{+}$and $\Omega_{++}$, invariant under $T$, such that $T$ restricted to $\Omega_{0}$ is of zero type, $T$ restricted to $\Omega_{+}$is of weakly positive type, and T restricted to $\Omega_{++}$is of strongly positive type. Moreover, $\Omega_{++}$is a union of countably many measurable sets of finite measure which are invariant under $T$.

Proof. Let $\mathscr{J}=\left\{A \in \mathscr{B} ; T^{-1} A=A\right.$ and $\left.m(A)<\infty\right\}$. Since $m$ is $\sigma$-finite, there exist countably many sets $A_{n}$ in $\mathscr{F}$ such that $\Omega_{++}=$ $\mathrm{U}_{n} A_{n}$ is the union of $\mathscr{F}_{\text {. }}$ Let $E \subset \Omega_{++}$be any measurable set of positive measure. Then $m(E \cap A)>\varepsilon$ for some $A \in \mathscr{J}$ and $\varepsilon>0$. Hence we have

$$
\limsup _{N \rightarrow \infty} \frac{1}{N} \sum_{k=0}^{N-1} m\left(T^{-k}(E \cap A) \cap A\right)>0,
$$

from which it follows that

$$
\operatorname{limsum}_{N \rightarrow 1} \frac{1}{N} \sum_{k=0}^{N-1} m\left(T^{-k} E \cap E\right)>0 .
$$

Thus $T$ restricted to $\Omega_{++}$is of strongly positive type. On the other hand, since $\Omega-\Omega_{++}$contains no invariant measurable set of finite positive measure, it follows (cf. [2, pp. 40-41] and [3]) that

$$
\lim _{N \rightarrow \infty} \frac{1}{N} \sum_{k=0}^{N-1} m\left(T^{-k} A \cap A\right)=0
$$

for any measurable set $A \subset \Omega-\Omega_{++}$with $m(A)<\infty$. This together with [4, Theorem 2.1] implies that $\Omega-\Omega_{++}$decomposes into two measurable sets $\Omega_{0}$ and $\Omega_{+}$, invariant under $T$, such that $T$ restricted to $\Omega_{0}$ is of zero type and $T$ restricted to $\Omega_{+}$is of weakly positive type. The uniqueness of such a triple of measurable sets is easily checked, and hence we omit the details.

We note here that the part $\Omega_{++}$above is nothing less than the seat of the maximal finite equivalent invariant measure. This follows from [5, Theorem 8].

3. An application to ergodic theorems. The following definition is due to Brunel and Keane [1].

Definition. A sequence $k_{1}, k_{2}, \cdots$ of strictly increasing nonnegative integers is called uniform, if there exist

(i) a strictly $L$-stable $(X, \mathscr{M}, \mu, \varphi)$;

(ii) a $Y \in \mathscr{C l}$ such that $\mu(Y)>0=\mu(\partial Y)$, where $\partial Y$ denotes the boundary of $Y$; 
(iii) a point $y \in X$ such that $k_{i}=k_{i}(y, Y)$ for each $i$, where $k_{i}(y, Y)$ is defined recursively as:

$$
\begin{aligned}
& k_{1}(y, Y)=\min \left\{j \geqq 0 ; \varphi^{j} y \in Y\right\}, \\
& k_{i}(y, Y)=\min \left\{j>k_{i-1}(y, Y) ; \varphi^{j} y \in Y\right\} \quad(i>1) .
\end{aligned}
$$

Brunel and Keane showed in [1] that if $T$ is a measure preserving transformation on a finite measure space then, for every uniform sequence $k_{1}, k_{2}, \cdots$, the average

$$
\frac{1}{N} \sum_{i=1}^{N} f\left(T^{k_{i}} \cdot\right)
$$

converges in the mean and almost everywhere. In this section we shall extend this result to $\sigma$-finite and infinite measure spaces.

THEOREM 2. Let $T$ be a measure preserving transformation on a $\sigma$-finite and infinite measure space $(\Omega, \mathscr{B}, m)$. If $f \in L^{1}(\Omega, \mathscr{B}, m)$ and if $k_{1}, k_{2}, \cdots$ is a uniform sequence, then

$$
f^{*}(\omega)=\lim _{N \rightarrow \infty} \frac{1}{N} \sum_{i=1}^{N} f\left(T^{k i} \omega\right)
$$

exists almost everywhere and $f^{*} \in L^{1}(\Omega, \mathscr{B}, m)$.

Proof. Let $\Omega_{0}, \Omega_{+}$and $\Omega_{++}$be as in Theorem 1 . Since $\Omega_{++}$is a union of countably many invariant measurable sets of finite measure, it follows from [1] that (2) exists almost everywhere on $\Omega_{++}$. The almost everywhere convergence of (2) on $\Omega_{0} \cup \Omega_{+}$can be shown as follows. Here it may and will be assumed without loss of generality that $f \geqq 0$ and $\Omega=\Omega_{0} \cup \Omega_{+}$. The Birkhoff individual ergodic theorem then implies that

$$
g(\omega)=\lim _{N \rightarrow \infty} \frac{1}{N} \sum_{j=0}^{N-1} f\left(T^{j} \omega\right)
$$

exists almost everywhere, $g \in L^{1}(\Omega, \mathscr{R}, m)$, and $g$ is invariant under $T$. Since $\Omega=\Omega_{0} \cup \Omega_{+}$by assumption, it follows that $g=0$ almost everywhere. This together with fact, established by Brunel and and Keane [1], that uniform sequences have positive density implies that Cesàro averages of $f\left(T^{k_{i}} \omega\right)$ converge almost everywhere to zero. The proof is complete.

REMARK. It follows easily from Theorem 2 that if $1 \leqq p<\infty$ and $f \in L^{p}(\Omega, \mathscr{B}, m)$, then

$$
f^{*}(\omega)=\lim _{N \rightarrow \infty} \frac{1}{N} \sum_{i=1}^{N} f\left(T^{k_{i}} \omega\right)
$$


exists almost everywhere and $f^{*} \in L^{p}(\Omega, \mathscr{B}, m)$.

The proof of the following theorem is similar to the one given by Krengel and Sucheston [4].

THEOREM 3. Let $T$ be a measure preserving transformation on a $\sigma$-finite and infinite measure space $(\Omega, \mathscr{R}, m)$. If $k_{1}, k_{2}, \cdots$ is a uniform sequence, $1<p<\infty$, and $f \in L^{p}(\Omega, \mathscr{R}, m)$, then

$$
\lim _{N \rightarrow \infty}\left\|\frac{1}{N} \sum_{i=1}^{N} f\left(T^{k_{i}} \cdot\right)-f^{*}\right\|_{p}=0 .
$$

Proof. Since $f^{*}=0$ almost everywhere on $\Omega_{0} \cup \Omega_{+}$, it suffices to show, under the assumption $\Omega=\Omega_{0} \cup \Omega_{+}$, that

$$
\lim _{N \rightarrow \infty}\left\|\frac{1}{N} \sum_{i=1}^{N} f\left(T^{k_{i}} \cdot\right)\right\|_{p}=0 \text {. }
$$

But clearly it suffices to show (3) for $f=1_{A}$ with $m(A)<\infty$. Since

$$
\left\|\frac{1}{N} \sum_{i=1}^{N} 1_{A}\left(T^{k_{i}} \cdot\right)\right\|_{p}^{p} \leqq\left\|\frac{1}{N} \sum_{i=1}^{N} 1_{A}\left(T^{k} \cdot\right)\right\|_{q}^{q}
$$

for $p>q>1$, it may and will assume without loss of generality that $p<2$. Set $\delta=p-1$, and define

$$
\left\{\begin{array}{l}
a_{N, k}=\frac{1}{N} \text { if } k \in\left\{k_{i} ; 1 \leqq i \leqq N\right\}, \\
a_{N, k}=0 \text { otherwise. }
\end{array}\right.
$$

Then

$$
\begin{aligned}
\left\|\frac{1}{N} \sum_{i=1}^{N} 1_{A}\left(T^{k_{i}} \cdot\right)\right\|_{p}^{p} & =\int\left(\sum_{k=0}^{\infty} a_{N, k} 1_{A}\left(T^{k} \omega\right)\right)^{1+\delta} d m(\omega) \\
& =\sum_{k=0}^{\infty} a_{N, k} \int_{T^{-k_{A}}}\left(\sum_{i=0}^{\infty} a_{N, i} 1_{A}\left(T^{i} \omega\right)\right)^{\delta} d m(\omega) .
\end{aligned}
$$

Let $\varepsilon>0$ be given. It follows from (1) that there exists a subset $S$ of the nonnegative integers having density zero such that

$$
\lim _{k \rightarrow \infty} m\left(T^{-k} A \cap A\right)=0,
$$

provided $k \notin S$. Choose a positive integer $n_{0}$ such that $|i-j|>n_{0}$ and $|i-j| \notin S$ imply

$$
m\left(T^{-i} A \cap T^{-j} A\right)<\varepsilon .
$$

Let $D\left(k, n_{0}\right)$ denote the set of nonnegative integers $i$ such that $|i-k| \leqq$ $n_{0}$. Since $0<\delta<1$, we have 


$$
\begin{aligned}
\int_{T^{-k_{A}}}( & \left.\sum_{i=0}^{\infty} a_{N, i} 1_{A}\left(T^{i} \omega\right)\right)^{\delta} d m(\omega) \\
\leqq & \int_{T^{-k_{A}}}\left(\sum_{i \in D\left(k, n_{0}\right)} a_{N, i} 1_{A}\left(T^{i} \omega\right)\right)^{\delta} d m(\omega) \\
& +\int_{T^{-k_{A}}}\left(\sum_{\substack{i \notin D\left(k, n_{0}\right) \\
|i-k| \notin S}} a_{N, i} 1_{A}\left(T^{i} \omega\right)\right)^{\delta} d m(\omega) \\
& +\int_{T^{-k_{A}}}\left(\sum_{\substack{i \notin D\left(k, n_{0}\right) \\
|i-k| \in S}} a_{N, i} 1_{A}\left(T^{i} \omega\right)\right)^{\delta} d m(\omega) \\
= & I(N, k)+I I(N, k)+I I I(N, k) .
\end{aligned}
$$

Since $\left|a_{N, i}\right| \leqq 1 / N$, we can choose an $N_{0}$ such that $N>N_{0}$ implies

$$
I(N, k) \leqq \int_{T^{-k_{A}}}\left(\frac{2 n_{0}+1}{N}\right)^{\delta} d m<\varepsilon
$$

On the other hand if we define for any given $\varepsilon_{1}>0$ a measurable set $G\left(N, k ; \varepsilon_{1}\right)$ by

$$
G\left(N, k ; \varepsilon_{1}\right)=\left\{\sum_{\substack{i \notin D\left(k, n_{0}\right) \\|i-k| \notin S}} a_{N, i} 1_{A}\left(T^{i} \omega\right)>\varepsilon_{1}\right\},
$$

then

$$
\begin{aligned}
I I(N, k) & \leqq \int_{T^{-k_{A}}}\left(\varepsilon_{1}^{\delta}+1_{G\left(N, k ; \varepsilon_{1}\right)}\right) d m \\
& \leqq \varepsilon_{1}^{\delta} m(A)+m\left(T^{-k} A \cap G\left(N, k ; \varepsilon_{1}\right)\right. \\
& <\varepsilon_{1}^{\delta} m(A)+\frac{\varepsilon}{\varepsilon_{1}},
\end{aligned}
$$

since $\varepsilon_{1} m\left(T^{-k} A \cap G\left(N, k ; \varepsilon_{1}\right)<\varepsilon\right.$ by (4). Hence it is sufficient to show that

$$
\lim _{N \rightarrow \infty} \sum_{k=0}^{\infty} a_{N, k} I I I(N, k)=0
$$

Clearly,

$$
\begin{aligned}
\sum_{k=0}^{\infty} a_{N, k} I I I(N, k) \leqq & \sum_{k=0}^{\infty} a_{N, k} \int_{T^{-k_{A}}}\left(\sum_{|i-k| \in S} a_{N, i}\right)^{\delta} d m \\
\leqq & \sum_{k=0}^{\infty} a_{N, k}\left(\sum_{\alpha \in S} a_{N, k+\alpha}\right)^{\delta} m(A) \\
& +\left(\sum_{\substack{\alpha \in S \\
\alpha \leqq k_{N}}} a_{N, k_{N}-\alpha}\right)^{\delta} m(A) .
\end{aligned}
$$

An argument similar to [3] can be applied to infer that

$$
\lim _{N \rightarrow \infty} \sum_{k=0}^{\infty} a_{N, k}\left(\sum_{\alpha \in S} a_{N, k+\alpha}\right)^{\delta}=0 \text {. }
$$


On the other hand, since

$$
\lim _{N \rightarrow \infty} \frac{k_{N}}{N}=\mu(Y)^{-1}<\infty
$$

by [1], we have

$$
\begin{aligned}
\lim _{N \rightarrow \infty}\left(\sum_{\substack{\alpha \in S \\
\alpha \leqq k_{N}}} a_{N, k_{N}-\alpha}\right) \\
\quad=\lim _{N \rightarrow \infty}\left(\frac{k_{N}}{N} \frac{\left|\left\{\alpha \in S ; \alpha \leqq k_{N}\right\}\right|}{k_{N}}\right)=0 .
\end{aligned}
$$

This completes the proof.

\section{REFERENCES}

1. A. Brunel and M. Keane, Ergodic theorems for operator sequences, Z. Wahrscheinlichkeitstheorie verw. Geb., 12 (1969), 231-240.

2. P. R. Halmos, Lectures on ergodic theory, The Mathematical Society of Japan, Tokyo (1956).

3. D. L. Hanson and G. Pledger, On the mean ergodic theorem for weighted averages,

Z. Wahrscheinlichkeitstheorie verw. Geb., 13 (1969), 141-149.

4. U. Krengel and L. Sucheston, On mixing in infinite measure spaces, Z. Warhscheinlichkeitstheorie verw. Geb., 13 (1969), 150-164.

5. L. Sucheston, On existence of finite invariant measures, Math. Z., 86 (1964), 327336 .

Received October 5, 1971 and in revised form February 11, 1972.

Josai University, SAKado, SaItama, JaPan 


\section{PACIFIC JOURNAL OF MATHEMATICS}

\section{EDITORS}

\section{H. SAMELSON}

Stanford University

Stanford, California 94305

C. R. Новву

University of Washington Seattle, Washington 98105

\section{J. DuGundJI}

Department of Mathematics University of Southern California Los Angeles, California 90007

RICHARD ARENS

University of California Los Angeles, California 90024

\section{ASSOCIATE EDITORS}
E. F. BECKENBACH
B. H. NeumanN
F. WOLF
K. YoSHIDA

\section{SUPPORTING INSTITUTIONS}

\author{
UNIVERSITY OF BRITISH COLUMBIA \\ CALIFORNIA INSTITUTE OF TECHNOLOGY \\ UNIVERSITY OF CALIFORNIA \\ MONTANA STATE UNIVERSITY \\ UNIVERSITY OF NEVADA \\ NEW MEXICO STATE UNIVERSITY \\ OREGON STATE UNIVERSITY \\ UNIVERSITY OF OREGON \\ OSAKA UNIVERSITY
}

\author{
UNIVERSITY OF SOUTHERN CALIFORNIA \\ STANFORD UNIVERSITY \\ UNIVERSITY OF TOKYO \\ UNIVERSITY OF UTAH \\ WASHINGTON STATE UNIVERSITY \\ UNIVERSITY OF WASHINGTON \\ $*{ }^{*}$
AMERICAN MATHEMATICAL SOCIETY
NAVAL WEAPONS CENTER
}

The Supporting Institutions listed above contribute to the cost of publication of this Journal, but they are not owners or publishers and have no responsibility for its content or policies.

Mathematical papers intended for publication in the Pacific Journal of Mathematics should be in typed form or offset-reproduced, (not dittoed), double spaced with large margins. Underline Greek letters in red, German in green, and script in blue. The first paragraph or two must be capable of being used separately as a synopsis of the entire paper. The editorial "we" must not be used in the synopsis, and items of the bibliography should not be cited there unless absolutely necessary, in which case they must be identified by author and Journal, rather than by item number. Manuscripts, in duplicate if possible, may be sent to any one of the four editors. Please classify according to the scheme of Math. Rev. Index to Vol, 39. All other communications to the editors should be addressed to the managing editor, Richard Arens, University of California, Los Angeles, California, 90024.

50 reprints are provided free for each article; additional copies may be obtained at cost in multiples of 50 .

The Pacific Journal of Mathematics is issued monthly as of January 1966. Regular subscription rate: $\$ 48.00$ a year (6 Vols., 12 issues). Special rate: $\$ 24.00$ a year to individual members of supporting institutions.

Subscriptions, orders for back numbers, and changes of address should be sent to Pacific Journal of Mathematics, 103 Highland Boulevard, Berkeley, California, 94708.

PUBLISHED BY PACIFIC JOURNAL OF MATHEMATICS, A NON-PROFIT CORPORATION

Printed at Kokusai Bunken Insatsusha (International Academic Printing Co., Ltd.), 270, 3-chome Totsuka-cho, Shinjuku-ku, Tokyo 160, Japan. 


\section{Pacific Journal of Mathematics}

\section{Vol. 44, No. $2 \quad$ June, 1973}

Tsuyoshi Andô, Closed range theorems for convex sets and linear liftings . . . . . . 393

Richard David Bourgin, Conically bounded sets in Banach spaces . . . . . . . . . 411

Robert Jay Buck, Hausdorff dimensions for compact sets in $R^{n} \ldots \ldots \ldots \ldots \ldots \ldots . \ldots 421$

Henry Cheng, A constructive Riemann mapping theorem ................ 435

David Fleming Dawson, Summability of subsequences and stretchings of

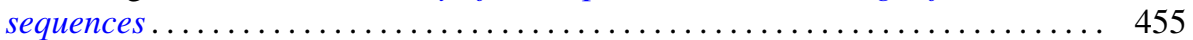

William Thomas Eaton, A two sided approximation theorem for 2-spheres ....... 461

Jay Paul Fillmore and John Herman Scheuneman, Fundamental groups of compact complete locally affine complex surfaces ....................... 487

Avner Friedman, Bounded entire solutions of elliptic equations . . . . . . . . . . . 497

Ronald Francis Gariepy, Multiplicity and the area of an $(n-1)$ continuous

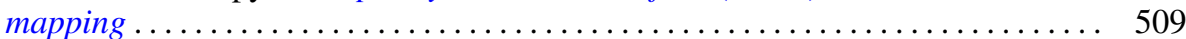

Andrew M. W. Glass, Archimedean extensions of directed interpolation groups . . . . 515

Morisuke Hasumi, Extreme points and unicity of extremum problems in $H^{1}$ on

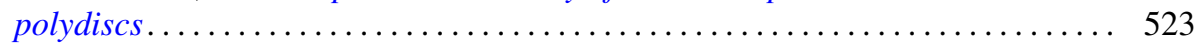

Trevor Ongley Hawkes, On the Fitting length of a soluble linear group . . . . . . 537

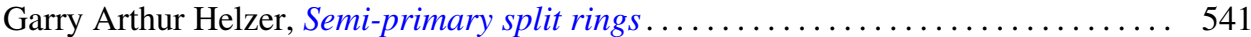

Melvin Hochster, Expanded radical ideals and semiregular ideals . . . . . . . . . 553

Keizō Kikuchi, Starlike and convex mappings in several complex variables . . . . . . 569

Charles Philip Lanski, On the relationship of a ring and the subring generated by its

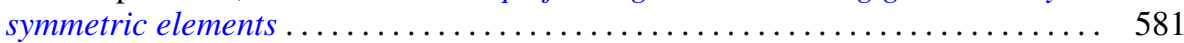

Jimmie Don Lawson, Intrinsic topologies in topological lattices and semilattices ........................................... 593

Roy Bruce Levow, Counterexamples to conjectures of Ryser and de Oliveira ...... 603

Arthur Larry Lieberman, Some representations of the automorphism group of an infinite continuous homogeneous measure algebra ..........

William George McArthur, $G_{\delta}$-diagonals and metrization theorems $\ldots .$.

James Murdoch McPherson, Wild arcs in three-space. II. An invariant of

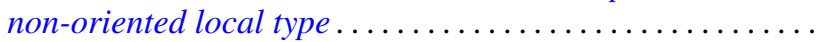

H. Millington and Maurice Sion, Inverse systems of group-valued measures ...

C. Edward Moore, Concrete semispaces and lexicographic separation of convex

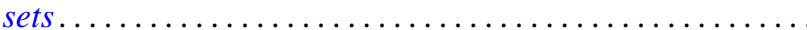

Jingyal Pak, Actions of torus $T^{n}$ on $(n+1)$-manifolds $M^{n+1}$.

Merrell Lee Patrick, Extensions of inequalities of the Laguerre and Turán type . . . . 675

Harold L. Peterson, Jr., Discontinuous characters and subgroups of finite index. . . . 683

S. P. Philipp, Abel summability of conjugate integrals . . . . . . . . . . . . . 693

R. B. Quintana and Charles R. B. Wright, On groups of exponent four satisfying an

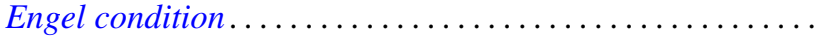

Marlon C. Rayburn, On Hausdorff compactifications. . . . . . . . . .

Martin G. Ribe, Necessary convexity conditions for the Hahn-Banach theorem in

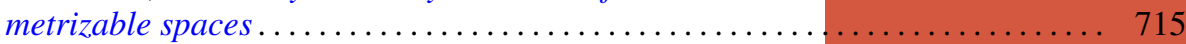

Ryōtarō Satō, On decomposition of transformations in infinite measure spaces .... 733

Peter Drummond Taylor, Subgradients of a convex function obtained from a

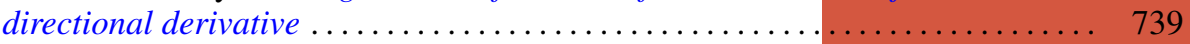

James William Thomas, A bifurcation theorem for $k$-set contractions . . . . . . . . 749 Clifford Edward Weil, A topological lemma and applications to real functions . . . . 757

Stephen Andrew Williams, A nonlinear elliptic boundary value problem . . ....... 767

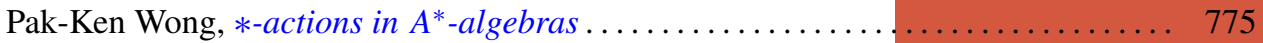

